\title{
Formulation of a novel drinking water quality index equation with the application of multi-criteria decision making techniques
}

Deepjyoti Deb ( $\sim$ ddeb210@gmail.com )

National Institute of Technology Agartala https://orcid.org/0000-0003-4358-5160

Tilottama Chakraborty

National Institute of Technology Agartala

Mrinmoy Majumder

National Institute of Technology Agartala

\section{Research Article}

Keywords: Water Quality, Water Quality Index, Analytical Hierarchy Process, Analytic Network Process

Posted Date: October 18th, 2021

DOl: https://doi.org/10.21203/rs.3.rs-764001/v1

License: (c) (i) This work is licensed under a Creative Commons Attribution 4.0 International License.

Read Full License 


\section{FORMULATION OF A NOVEL DRINKING WATER QUALITY INDEX EQUATION WITH THE APPLICATION OF MULTI-CRITERIA DECISION MAKING TECHNIQUES}

\section{Deepjyoti Deb, Tilottama Chakraborty, Mrinmoy Majumder}

Abstract Water Quality Index elucidates the complexity in assessing water quality by converting the results of various parameters into a single number for a precise interpretation of the condition of concerning water. The present study focuses on implementing MultiCriteria decision-making techniques, namely, Analytical Hierarchy Process and Analytical Networking Process, in estimating the relative weighted significance values of the water quality parameters based on three novel criteria like Cost, Potability, and Taste. The suggested Water Quality Index technique utilizes these weighted values of the water quality parameters in depicting and expressing the water quality level in the form of an index value. Dissolved Oxygen has emerged as the most persuasive factor in evaluating water quality for drinking purposes in this study. This paper has also suggested modifying the standard weighted arithmetic water quality index for higher accuracy in results. Furthermore, Sensitivity analysis is performed to corroborate the Multi-Criteria Decision Making approach in index assessment. The accuracy of the Water Quality Index analysis shall improve if a fixed set of criteria and their preference are asserted and justified based on which the water quality parameters are ranked. Their weighted significance values will be estimated accordingly.

Keywords: Water Quality, Water Quality Index, Analytical Hierarchy Process, Analytic Network Process.

\section{Deepjyoti Deb}

Postgraduate Hydro Informatics Engineering Student, 
National Institute of Technology Agartala, Tripura, India.

E-mail: ddeb210@gmail.com

Phone: 9674860529

\section{Mrinmoy Majumder}

Assistant Professor, Hydro-Informatics Engineering (Under Civil Engineering. Department), National Institute of Technology Agartala, Tripura, India.

E-mail: mmajumder15@gmail.com

\section{Tilottama Chakraborty}

Assistant Professor, Hydro-Informatics Engineering (Under Civil Engineering. Department), National Institute of Technology Agartala, Tripura, India.

E-mail: tilottama86@gmail.com

\section{LIST OF ABBREVIATIONS}

\begin{tabular}{l|l}
\hline Abbreviation & \\
\hline AHP & Analytical Hierarchy Process \\
\hline ANP & Analytic Network Process \\
\hline BOD & Biological Oxygen Demand \\
\hline CCMEWQI & Canadian Council Ministers of Environment Water Quality Index \\
\hline COD & Chemical Oxygen Demand \\
\hline DO & Dissolved Oxygen \\
\hline GIS & Geographic Information System \\
\hline GM & Geometric Mean \\
\hline IDW & Inverse Distance Weighting \\
\hline MCDM & Multi Criteria Decision Making \\
\hline NSFWQI & National Sanitation Foundation Water Quality Index \\
\hline OWQI & Oregon Water Quality Index \\
\hline
\end{tabular}




\begin{tabular}{l|l}
\hline TDS & Total Dissolved Solids \\
\hline TSS & Total Suspended Solids \\
\hline TPC & Total plate count \\
\hline WAWQI & Weighted Arithmetic Water Quality Index \\
\hline WHO & World Health Organization \\
\hline WQI & Water Quality Index \\
\hline
\end{tabular}

\section{INTRODUCTION}

A country's well-being depends mainly on its quality of water, surrounding air, and ecological balance. It has become substantial to evaluate the water quality that we consume because of increasing pollution and contaminants in the surface water. Water quality is analyzed based on an extensive set of physio-chemical and biological parameters. It is advisable to consume the water only if it falls under the predefined water quality standards set by World Health Organization (WHO) for various parameters. The authors in their study, evaluate groundwater condition of villages affected by industrial growth in Ranebennur taluk, Karnataka, India, in which the majority of the groundwater samples (collected from bore wells) has been found appropriate for drinking and irrigation purposes but with a risk of decline in the level of groundwater [21]. In this study, the authors had adopted the application of Geographic Information System (GIS) in outlining the present water quality of Tapi basin, Gujarat, and uses an interpolation technique, known as Inverse Distance Weighting (IDW) to determine spatial propagation of water quality parameters by Biological Oxygen Demand (BOD), Chemical Oxygen Demand (COD), chloride and Total Dissolved Solids (TDS) [11]. Water quality is considered a criterion to check the suitability of water for a distinct purpose appertaining to chosen physicochemical and biological characteristics [2]. Water that contains a substantial number of suspended solids and other matter particles and is 
exceedingly turbid might work well for an agricultural activity but is not convenient for drinking purposes.

Seven water quality parameters, namely, TDS, TSS, Hardness, pH, BOD, DO, have been considered in the present study for determining the quality of the water samples. TDS represents dissolved composite matter of inorganic and organic nature that exhibits liquid in tiny, ionized, or micro-granulated suspended form. From a water consumption point of view, TSS should be as low as possible. Hard waters generate scaling in water pipelines, heaters, furnaces, and other elements [12]. Higher DO value improves the taste of the drinking water (Dabkowski 2012). TPC method depends on the augmentation of bacteria organized as colonies on a nutrient medium to get discernible to the naked eye. Accordingly, counting of colonies on a plate is carried out [17]. $\mathrm{pH}$ shows the intensity of acid or essential condition by pointing out the hydrogen ion activity.

Water Quality Index (WQI) provides a distinct idea of the concerned water quality by incorporating the composite influence of several parameters on the implied water quality [3]. Horton (1965) developed a water quality index in which proper allocation of arithmetic weight was given to the water quality parameters suitable to their interpretation. The authors had studied and assessed groundwater of nine villages of Satlasana Taluka, Mehsana district, Gujarat, India, with the help of the Weighted Average Water Quality Index (WAWQI) and Canadian Council Ministers of Environment Water Quality Index (CCMEWQI) for which groundwater samples from fifty sources were taken. It was found that around $46 \%$ of the groundwater in Satlasana was in good condition as per WAWQI, whereas $54 \%$ of the groundwater quality came out as marginal using CCMEWQI [10]. The groundwater quality of Pavagada taluk in the Tumkur district was studies, which had experienced deficit rainfall resulting in a decline in the groundwater level in the bore wells and led to groundwater contamination. The assessment was done using the water quality index, and GIS Techniques 
shows that more than $90 \%$ of the groundwater samples are in the "excellent" \& "good" category. The fluoride content in the water has affected the WQI [14].

\subsection{Motivation}

Water Quality Index is a very conducive mode to enumerate the quality of the water. Several standard methods have been prescribed for computing the WQI value. But every technique has certain advantages and disadvantages. National Sanitation Foundation WQI (NSFWQI) method does not represent any particular use of water. The method of assigning weighting factors is also not apt as it is not based on any specific criterion. Nine fixed parameters are used in the index calculation. There are other critical water quality parameters also which has not been taken into consideration in this process. Although CCMEWQI is easy to evaluate and Statistically simplify complex multivariate data, this method can be easily manipulated. If very few parameters are used, then F1 may not work correctly, resulting in an inappropriate result [18]. In Oregon Water Quality Index, all the parameters are assigned equal weightage, as a result of which the critical parameter influencing the quality of water cannot be readily determined. The present study can overcome this drawback with the help of MCDM techniques and sensitivity analysis of WQI. The present study is based on the WAWQI method. But the approach of this method does not hold good for specific parameters like $\mathrm{pH}$ and DO. Thus, few modifications have been suggested in this study to improve the accuracy of obtaining improved WQI value, further discussed in section 4. The methodology of this process is explained in section 2.2.

Most of the WQI mentioned above processes have used the absolute approach in assigning priority value to the water quality parameters. This study has emphasized the relative approach in giving weightage to various parameters with the help of Multi-Criteria Decision Making (MCDM) techniques. This approach will also tell us about the most significant parameter in determining water quality based on the different criteria set by users 
across the world. MCDM techniques also serve the purpose of feature selection. Based on the weighted significance values, only the most consequential parameters are considered for determining the WQI. This approach will also minimize the time and cost incurred in analyzing the physio-chemical and biological parameters of the water samples.

\subsection{Objectives of the Study}

The objective of the present study is to establish a new process for the computation of water quality index with the help of the MCDM techniques based on three criteria, namely, Cost, Potability, and Taste. The study also shows AHP and ANP in calculating the priority weights for the water quality parameters. It suggests few adaptations in the standard WAWQI method for better preciseness in the index value. The paper also investigates the purity of drinking water collected from the water purifiers installed in the thirteen sampling sites of Jirania, Agartala, India. Finally, the study validates the competence of the MCDM based WQI approach in allocating weightage of priority to the water quality parameters with Sensitivity Analysis.

\section{METHODS ADOPTED}

The study involves testing the water samples based on seven parameters using various techniques discussed in section 2.1. Then the water quality index is computed, keeping the WAWQI as the reference but adopting few modifications for better accuracy in the results. The detailed process of conventional WAWQI has been discussed in section 2.2. MCDM techniques, namely AHP and ANP have been used in our study to obtain the parameters' relative weights. Pivotal steps of these techniques have been elaborated in sections 2.3 and 2.4 .

\subsection{Water Quality Analysis through Physio-Chemical and Biological parameters}

Based on the seven selected parameters, water quality in thirteen collected sampling stations is assessed. TDS concentration of various collected samples is measured with the help of a 
TDS meter [1]. TSS is evaluated using the filter paper method [6]. The EDTA Titration process determines the Hardness of various water samples. The dissolved oxygen value of all the collected samples is obtained from the DO meter [5]. For the BOD concentration of each of the samples, $300 \mathrm{ml}$ of the water sample is kept in the BOD incubator for five days. Total Bacterial count has been done using the spread plate technique [16]. HORIBA multiparameter water quality checker has been used to determine the $\mathrm{pH}$ of the water samples. Table 1 given below shows the permissible limits concerning water quality parameters as per World Health Organization [22].

Table 1 Drinking Water standards as per World Health Organization (WHO) in the third edition (2008) and fourth edition (2011) for various water quality parameters

\begin{tabular}{|c|c|}
\hline Water Quality Parameter & Acceptable Limit \\
\hline Total Dissolved Solids (mg/l) & 200 \\
\hline Total suspended Solids (mg/l) & 300 \\
\hline Hardness (mg/l) & 5 \\
\hline Dissolved Oxygen (mg/l) & 5 \\
\hline Biological Oxygen Demand (mg/l) & 300 \\
\hline Total Plate Count Test (Colonies) & 8.5 \\
\hline pH & \\
\hline
\end{tabular}

\subsection{Weighted Arithmetic Water Quality Index (WAWQI)}

Calculation of WQI Using Weighted Arithmetic Water Quality Index Method (Standard Expression) [15]: 


$$
\mathrm{WQI}=\sum_{i=1}^{n} \frac{W i Q i}{\sum W i}
$$

$\mathrm{Qi}=\mathrm{Quality}$ rating for the $\mathrm{i}^{\text {th }}$ water quality parameters

Wi: Unit weight for the $i^{\text {th }}$ parameters

$$
\mathrm{Qi}=\left(\frac{(\mathrm{Va}-\mathrm{Vi})}{(\mathrm{Vs}-\mathrm{Vi})}\right) \times 100
$$

$\mathrm{V}_{\mathrm{a}}$ : actual value obtained of the $\left(\mathrm{i}^{\text {th }}\right)$ parameter at a given sampling station.

$\mathrm{V}_{\mathrm{i}}$ : the ideal value of the specific parameter ( 0 for all parameters excepts $\mathrm{pH}$ and DO, which are 7.0 and $14.6 \mathrm{mg} / \mathrm{lit}$, respectively).

$\mathrm{V}_{\mathrm{s} .}$ : standard value

As per the prescribed method, unit weight for various water quality parameters is inversely proportional to the recommended standards for the corresponding parameters.

$$
\mathrm{Wi}=\frac{\mathrm{K}}{\mathrm{Si}}
$$

Wi: unit weight for the $\mathrm{i}^{\text {th }}$ parameters

Si: standards value for the $\mathrm{i}^{\text {th }}$ parameters

$\mathrm{K}$ : relative constant

$$
\mathrm{K}=\frac{1}{\Sigma\left(\frac{1}{\mathrm{Si}}\right)}
$$

The range of WQI for various probable uses of water has been shown in table 2 . Furthermore, the condition of water based on the WQI spectrum is also given for a precise understanding of the clarity of the water [19].

Table 2 Water Quality Index (WQI) range, status, and possible usage of water sample (Brown et al. 1972)

\begin{tabular}{|l|l|l|}
\hline WQI & Water Quality & Use \\
\hline
\end{tabular}




\begin{tabular}{|c|c|c|}
\hline & rating & \\
\hline $0-25$ & Excellent & Drinking, irrigation, and industrial \\
& & purpose \\
\hline $25-50$ & Good & Drinking, irrigation, and industrial \\
\hline $50-75$ & Poor & Irrigation and industrial purpose \\
\hline $75-100$ & Very Poor & For irrigation purpose \\
\hline Above 100 & Unsuitable for & Proper treatment is required for any \\
& drinking purposes & usage \\
\hline
\end{tabular}

\subsection{Analytic Hierarchy Process}

Analytical Hierarchy Process (AHP) is an MCDM method where a layered framework is developed. In this method, the designed hierarchical structure keeps the goal at the top level, the criteria at the second stage, and the alternatives at the third level. The author studies the utilization of water quality index and GIS-based analytic hierarchy process in evaluating groundwater quality in the wet and dry seasons of Sivas province (Turkey), where the findings showed that $91.66 \%$ of groundwater samples collected during the wet season and around $77 \%$ of samples collected during the dry season are apt for consumption purpose [9]. In this study, the application of combined fuzzy inclusive evaluation and analytic hierarchy process in determining risk assessment of large-scale seawater desalination projects based on a comprehensive evaluation of an incorporated undefined and analytical hierarchy process method in which two levels of risk indicators are recognized. The analyzed reports suggest 
that all the concerned projects' overall risks are at the "Shallow" level [23]. AHP is carried out by following the below-mentioned steps stated in table 3 in chronological order.

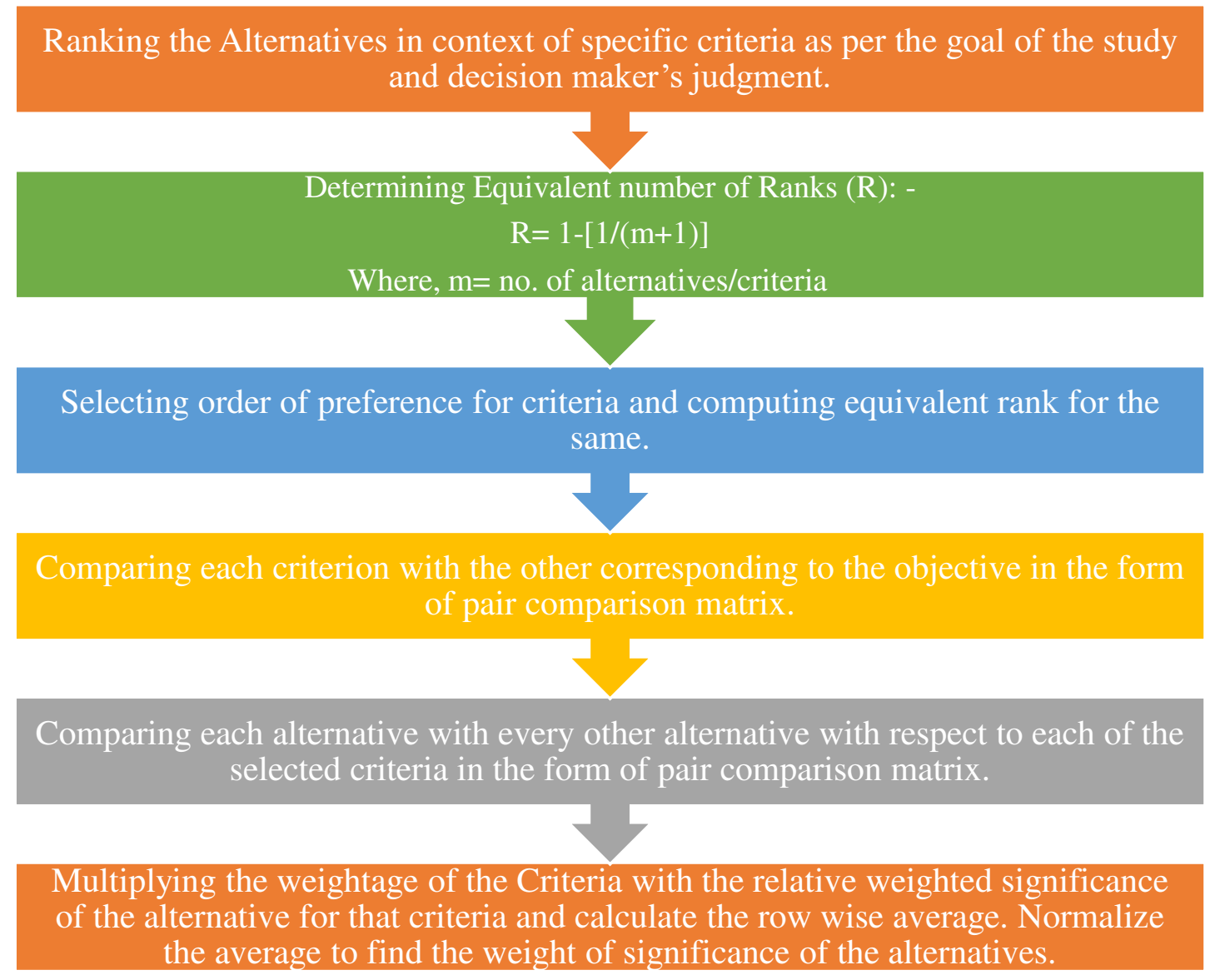

Figure 1 Major Steps followed in Analytical Hierarchy Process

\subsection{Analytic Network Process}

The Analytic Network Process (ANP) is a decision-finding technique that is also a generalization of AHP. In this MCDM technique, a network is developed consisting of criteria, sub-criteria, and alternatives represented equally as nodes. Each of these nodes might be compared with each other. This depicts that the ranking of alternatives and criteria in the specific problem depend on each other. The authors, in their study, used a suitable technique that consolidates GIS, ANP, and remote sensing for assessing and delineating susceptibility 
of flood in which ANP mathematical model was used to estimate the relative weighted significance of the several floods influencing factors [4].

In ANP, the six steps used in the AHP for the computation of weighted significance to the criteria will be carried forward. Up next, the criteria are compared with each other concerning each of the alternatives. As a result, each criterion will have another weightage of significance. In the final step, multiply the weighted relevance of criteria with the weighted relevance of alternatives (computed in the sixth step of AHP) and calculate the row-wise average. Normalize the average to find the updated relative weights of alternatives [20].

\subsection{Shannon's entropy}

Shannon's entropy was used in this study to aggregate the different ranking results derived from AHP and ANP MCDM techniques. This method calculates the entropy measure of each of the ranking methods and finds the weights of the selected alternatives accordingly.

\subsection{Sensitivity Analysis}

The study of the response of an output variable in context to alteration of input variables is known as the sensitivity analysis [13]. In this research, the one-factor-at-a-time (OFAT) sensitivity analysis method has been performed to define predominant parameters affecting the water quality Index for drinking purposes calculated through the proposed process.

\section{STUDY AREA}

\subsection{General Information}

The present study is conducted in the small town of Agartala, Tripura, India. The fundamental research is carried out in thirteen blocks of an educational institute in Jirania, Agartala. The study area Jirania $\left(23.8132^{\circ} \mathrm{N}, 91.4362^{\circ} \mathrm{E}\right)$, is located on the banks of the Saidra River (Fig.1). 


\subsection{Selecting Sampling location}

The comprehensive study is conducted in thirteen different blocks scattered across the educational institute in Jirania, Tripura. The sampling stations have been named as S1, S2, S3.... S13.

\subsection{Sample Collection}

One of the study's objectives is to check the efficiency of the water purifiers installed in the thirteen sampling stations; thus, two water samples have been collected from each one of the blocks for comparative analysis. The first sample comprises the tap water (Untreated water), and the second sample has been taken from the water purifier (Treated water). The tap water sample is named 'INLET,' and the treated water collected from the installed water purifier is called 'OUTLET.' Figure 2 shows the Study area of Jirania derived from Google Earth Pro software.

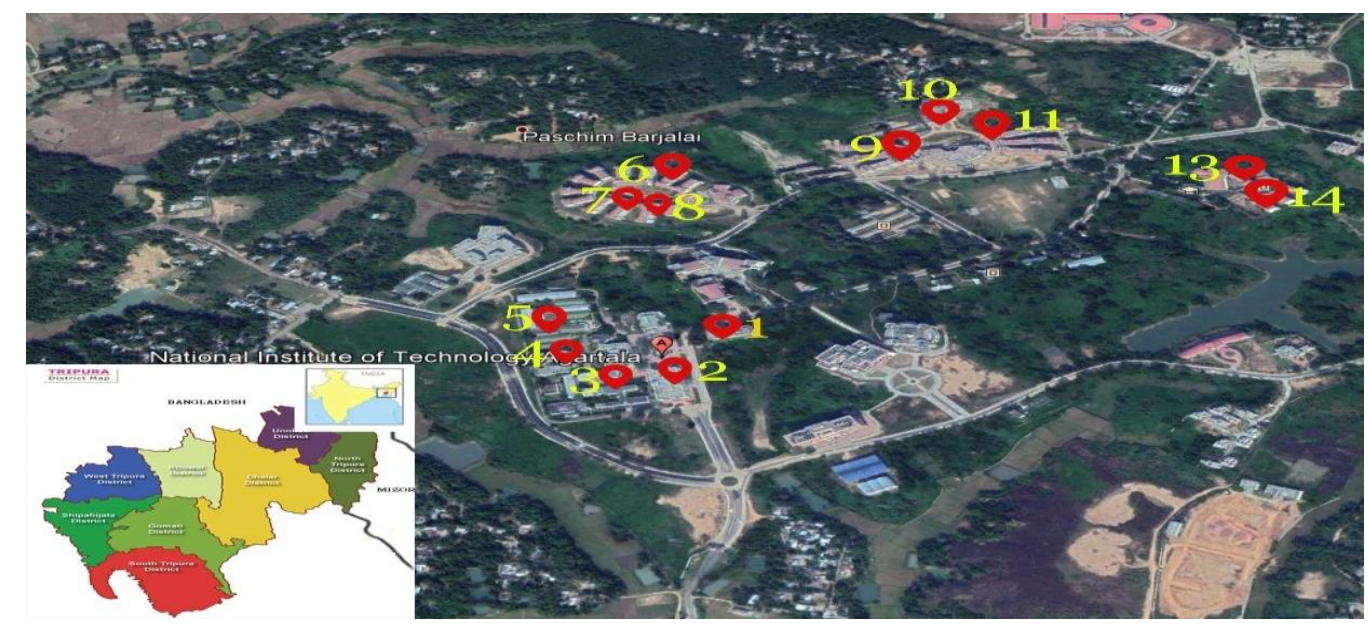

Figure 2 Location of the study area

\section{METHODOLOGY}

All the water samples (both Inlet and Outlet) were collected from different sources, and then they were analyzed for various physicochemical and biochemical parameters. The following 
parameters, namely TDS, TSS, pH, BOD, DO, TPC, and Hardness, are selected to assess drinking water quality in the study and are analyzed accordingly. All the values were compared with WHO standards. The efficiency of the water purifiers in cleaning the untreated water was checked by comparative analysis of Inlet and Outlet water samples.

Up next is finding out the relative weighted significance values or the priority value of the seven water quality parameters using MCDM techniques. Three novel criteria, namely, "Cost," "Potability," and "Taste," have been considered for performing AHP and ANP. Testing the parameter that involves maximum cost is ranked one under the criterion "Cost," and the alternative that requires the least cost in its testing is rated 7. Hardness test involves significantly less cost as compared to other parameters. Hence, under the 'Cost' criterion, it has been ranked in the first place.

Similarly, Dissolved oxygen contributes to the augmented taste of drinking water. So, this parameter is rated as the first concerning criterion 'Taste.' Potability refers to cleaner water free from polluted contaminants and other wastes. Bacterial presence majorly affects the Potability of drinking water. Therefore, TPC is ranked first under the criterion 'Potability.' The priority values obtained from Analytical Hierarchical Process have been compared with Analytic Network Process. Shannon's entropy weighted measure has been applied to aggregate dissimilar ranking results obtained from the two MCDM methods. Thus, the Aggregated Weighted Measure values $\left(\mathrm{W}_{\mathrm{i}}\right)$ of all the seven water quality parameters have been received.

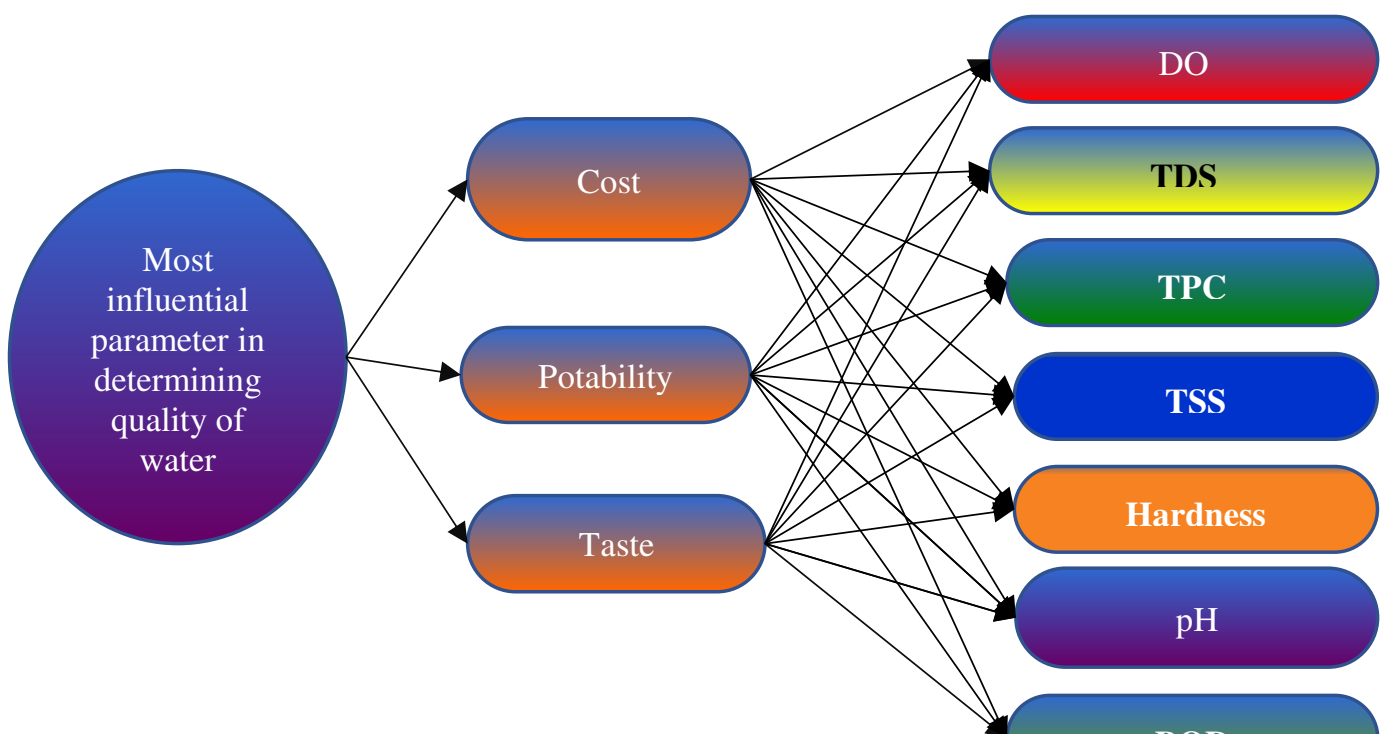


Figure 3 List of criteria and alternatives used in Analytical Hierarchy Process

Calculation of the Water Quality Index of all the treated and untreated waters samples has been carried out, taking into account the aggregated weighted values of the parameters and the results of the samples. Thus the steps for the proposed MCDM-WAWQI approach are given below:

First Step - Relative Weightage value (Wi) of all the selected water parameters is found out with the help of MCDM Techniques. The summation of all the weights is 1 .

Second Step- Assigning of a quality rating scale for each parameter, as below:

$$
Q i=\left|\frac{(V a-V i)}{(V s-V i)}\right| \times 100
$$

$\mathrm{Va}$ is the observed value of the parameter

$\mathrm{Vi}$ is the ideal value of the water quality parameter (For most cases, $\mathrm{Vi}=0$, e.g., TDS, TSS, HARDNESS, etc. But for $\mathrm{pH}, \mathrm{Vi}=7$ and Dissolved Oxygen, $\mathrm{Vi}=14.6 \mathrm{mg} / \mathrm{l}$ )

Vs. is the standard value as per WHO.

$$
W Q I=\sum_{i=1}^{n} \frac{W i Q i}{\sum W i}
$$

Wi is the relative unit weights obtained from MCDA methods for $i^{\text {th }}$ parameter The standard formula for Qi does not hold well for a few parameters such as $\mathrm{pH}$ and DO. The significance of the absolute sign in the procedure of Quality rating $\left(\mathrm{Q}_{\mathrm{i}}\right)$ has been discussed in Appendix 1. A summary of the entire work of the study has been given in figure 4 . 
- Collection of water samples from thirteen sampling stations

- Performing Physio-chemical and biological analysis on the water samples

- Finding out the weighted significance values of the water quality parameters with the integration of MCDM techniques and Shanon's Entropy weighted measure.

- Computing Water Quality Index of all the water samples using proposed MCDM-WAWQI approach

- Comparison of the proposed MCDM- WAWQI method with the original WAWQI method

- Comparative analysis of the Inlet and the Outlet water samples based on proposed WQI to check the degree of treatment by the water purifiers installed in the sampling stations

- Performing sensitivity analysis of WQI to validate the most influential water quality parameter in determining index calculation

Figure 4 Detailed methodology of the study

\section{RESULTS AND DISCUSSION}

The first and the most crucial stage in computing AHP and ANP are to rank the water quality parameters (Alternatives) for the selected criteria. After an extensive literature survey and experts' opinions in the Environmental and water resources engineering domain (table 3). Further the order of preference of each criterion has been given in table 4 based on the suitability for drinking purposes.

Table 3 Ranking the Alternatives as per the criteria corresponding to the objective of the study.

\begin{tabular}{c|c|c|c}
\hline Parameter & Cost & Potability & Taste \\
\hline TDS & 4 & 7 & 4 \\
\end{tabular}




\begin{tabular}{c|c|c|c} 
TSS & 2 & 3 & 6 \\
\hline DO & 3 & 2 & 1 \\
\hline BOD & 6 & 6 & 5 \\
\hline Hardness & 1 & 4 & 3 \\
\hline TPC & 7 & 1 & 2 \\
\hline $\mathrm{pH}$ & 5 & 5 & \\
\hline
\end{tabular}

Table 4 Order of preference for criteria

\begin{tabular}{c|c|c}
\hline Criteria & Rank & Equivalent Rank \\
\hline Potability & 1 & 0.75 \\
\hline Cost & 2 & 0.53 \\
\hline Taste & 3 & 0.25 \\
\hline
\end{tabular}

Table 5 shows the priority values of the seven water quality parameters evaluated from two MCDM techniques, namely, AHP and ANP. The results show that there has been no significant difference in values between the two techniques. Thus, the weights computed by AHP have been validated by another MCDM technique. Finally, the ensemble weights for parameters have been figured out by Shannon's Entropy weighted aggregate measure shown in tables 6 and 7.

Table 5 Relative Weighing factor of the alternatives as per AHP and ANP 


\begin{tabular}{c|c|c}
\hline Water Quality & Weighted Significance Values as & Weighted Significance Values as \\
Parameters & per AHP & per ANP \\
\hline TDS & 0.093 & 0.106 \\
\hline TSS & 0.171 & 0.156 \\
\hline DO & 0.207 & 0.213 \\
\hline BOD & 0.078 & 0.082 \\
\hline Hardness & 0.159 & 0.145 \\
\hline TPC & 0.168 & 0.156 \\
\hline pH & 0.126 & 0.142 \\
\hline
\end{tabular}

Based on the outcomes from AHP and ANP technique, it can be seen that Dissolved Oxygen (DO) is the most influential water quality parameter in deciding water quality for drinking purposes.

Table 6 Entropy weights of ranking methods

\begin{tabular}{c|c}
\hline Ranking Methods & Entropy Weights \\
\hline Analytical Hierarchy Process & 0.55 \\
\hline Analytic Network Process & 0.45 \\
\hline
\end{tabular}

Table 7 Ensemble weighted values and rank of the water quality parameters

\begin{tabular}{l|c|c}
\hline Water Quality Parameters & Weighted Aggregated Measure & Rank \\
\hline
\end{tabular}




\begin{tabular}{c|c|c}
\hline TDS & 0.099 & 6 \\
\hline TSS & 0.164 & 2 \\
\hline DO & $\mathbf{0 . 2 1 0}$ & $\mathbf{1}$ \\
\hline BOD & 0.080 & 7 \\
\hline Hardness & & 4 \\
\hline TPC & 0.153 & 3 \\
\hline $\mathrm{pH}$ & 0.163 & 5 \\
\hline
\end{tabular}

Figures 5 and 6 shows the pictorial representation of the values of the seven water quality parameters for all the sampling stations. Comparative analysis of the treated and untreated water samples in each of the locations has been shown. In most cases, the concentration of dissolved solids, suspended solids, Hardness, BOD, etc., is higher for untreated water samples (INLET).
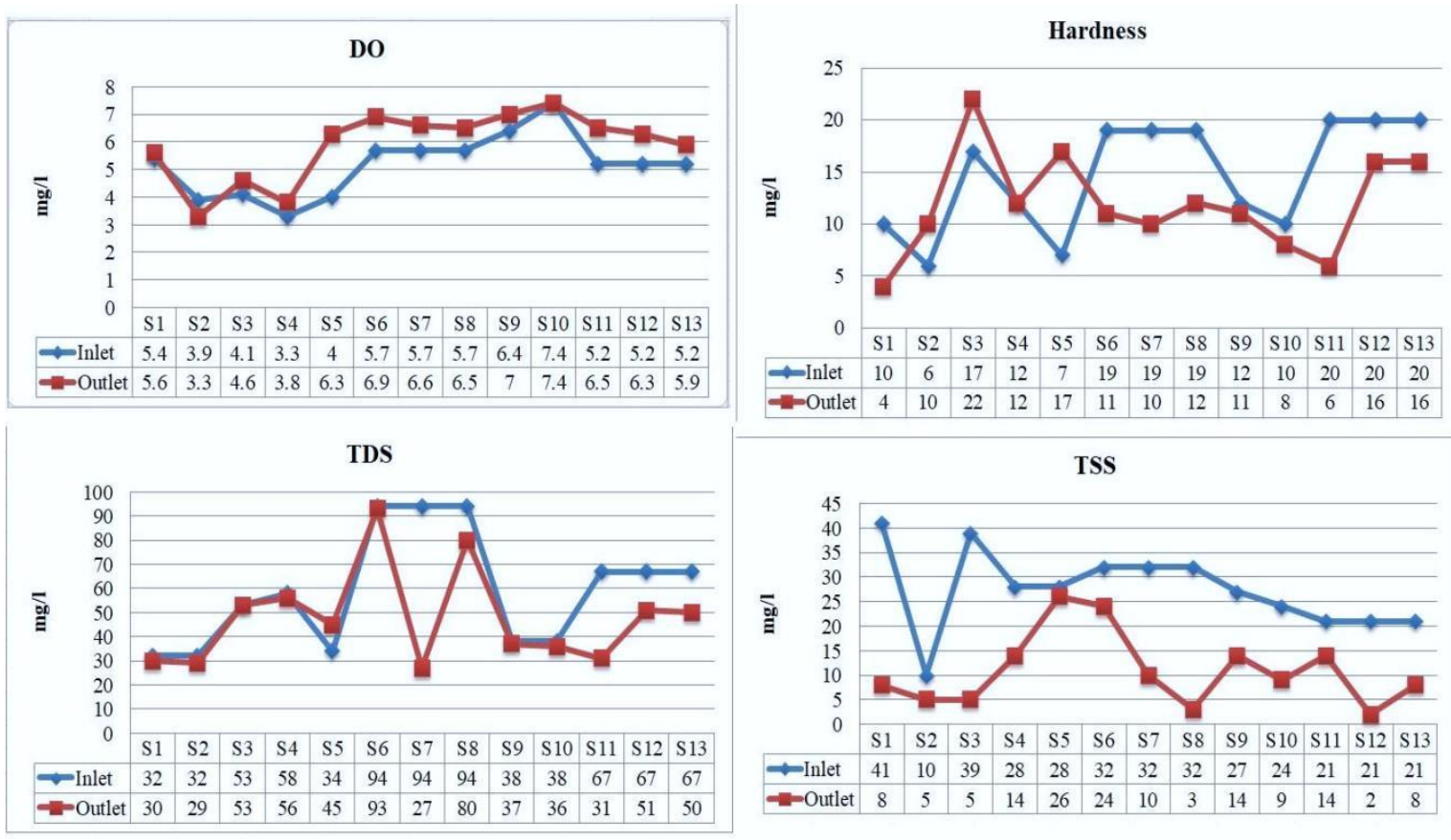
Figure 5 TDS, TSS, DO, and hardness results of the water samples

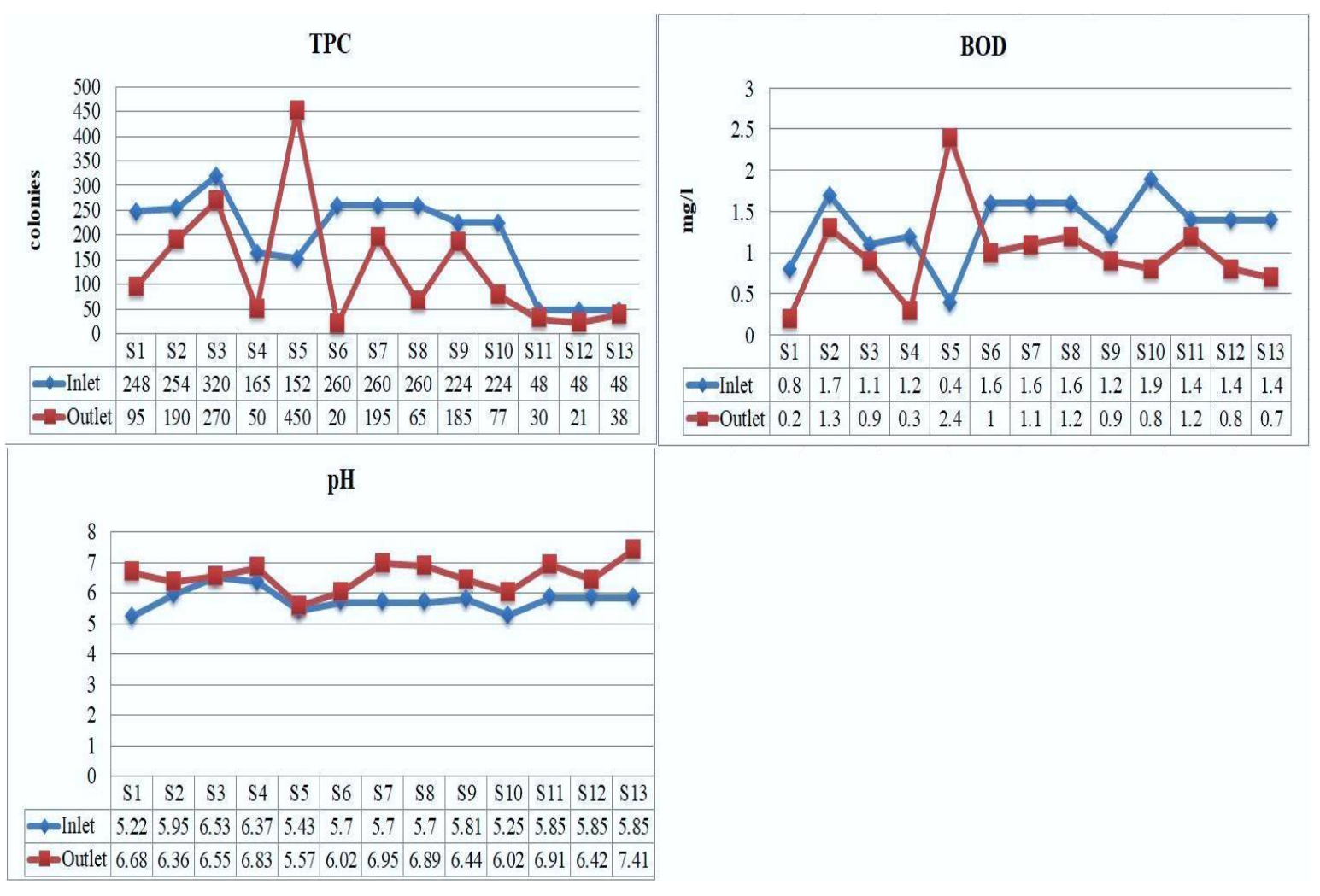

Figure 6 BOD, TPC, and pH results of the Inlet and Outlet water samples

Figures 7,8 , and 9 show the improvement in the water quality by the water purifiers installed in each of the sampling stations. The water purifier in S5 has shown the worst result, indicating it is not fit to consume water from this cleaner. 

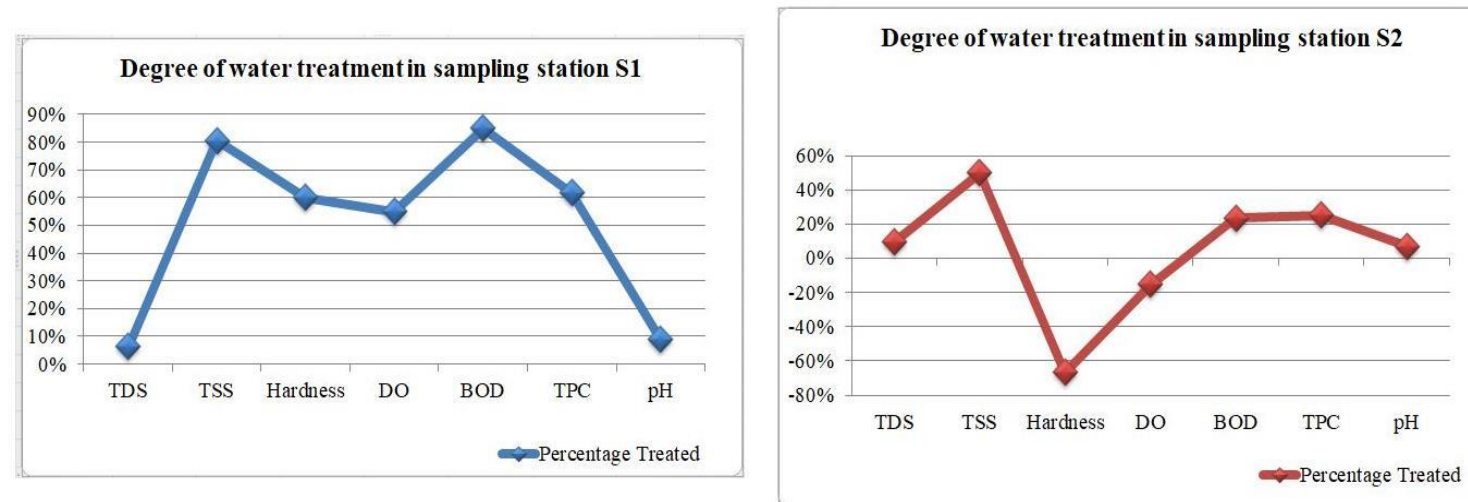

Degree of water treatment in sampling station S3
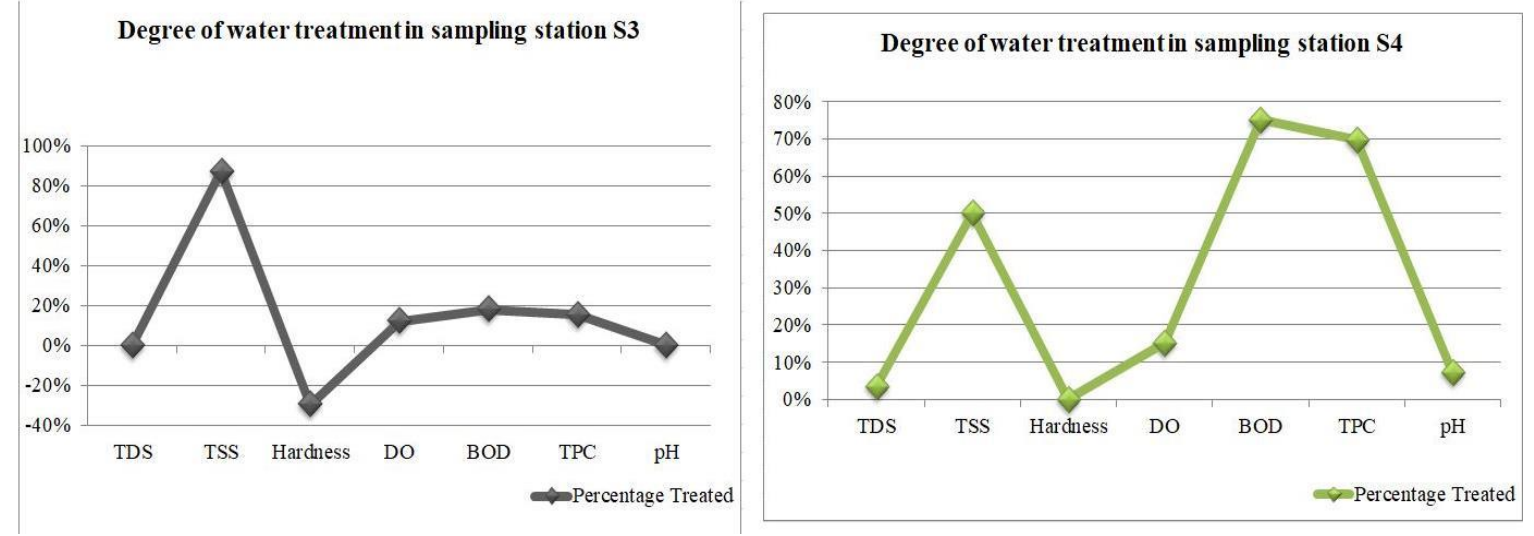

Figure 7 Efficiency of water purifiers installed in sampling stations S1, S2, S3, and S4
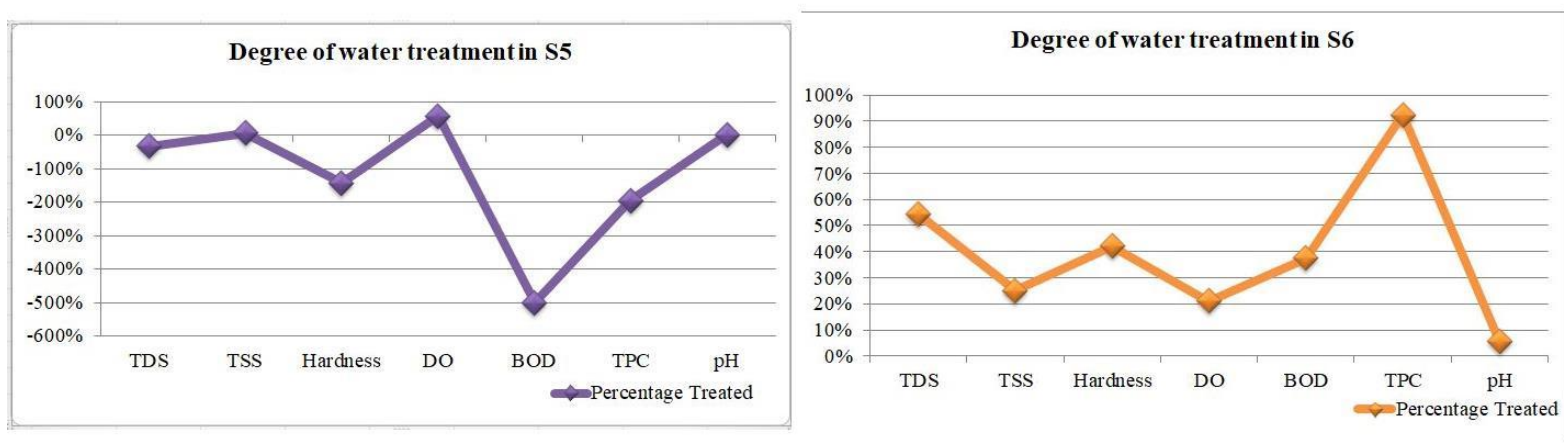

Degree of water treatment in $\mathrm{S} 7$
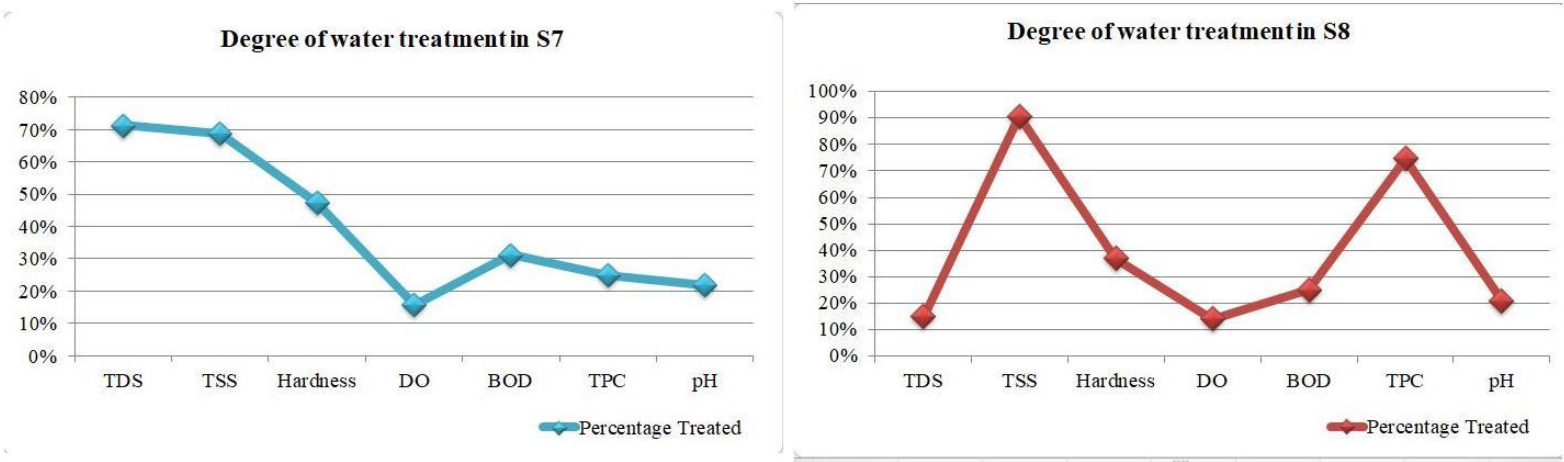

Figure 8 Efficiency of water purifiers installed in sampling stations S5, S6, S7, and S8 

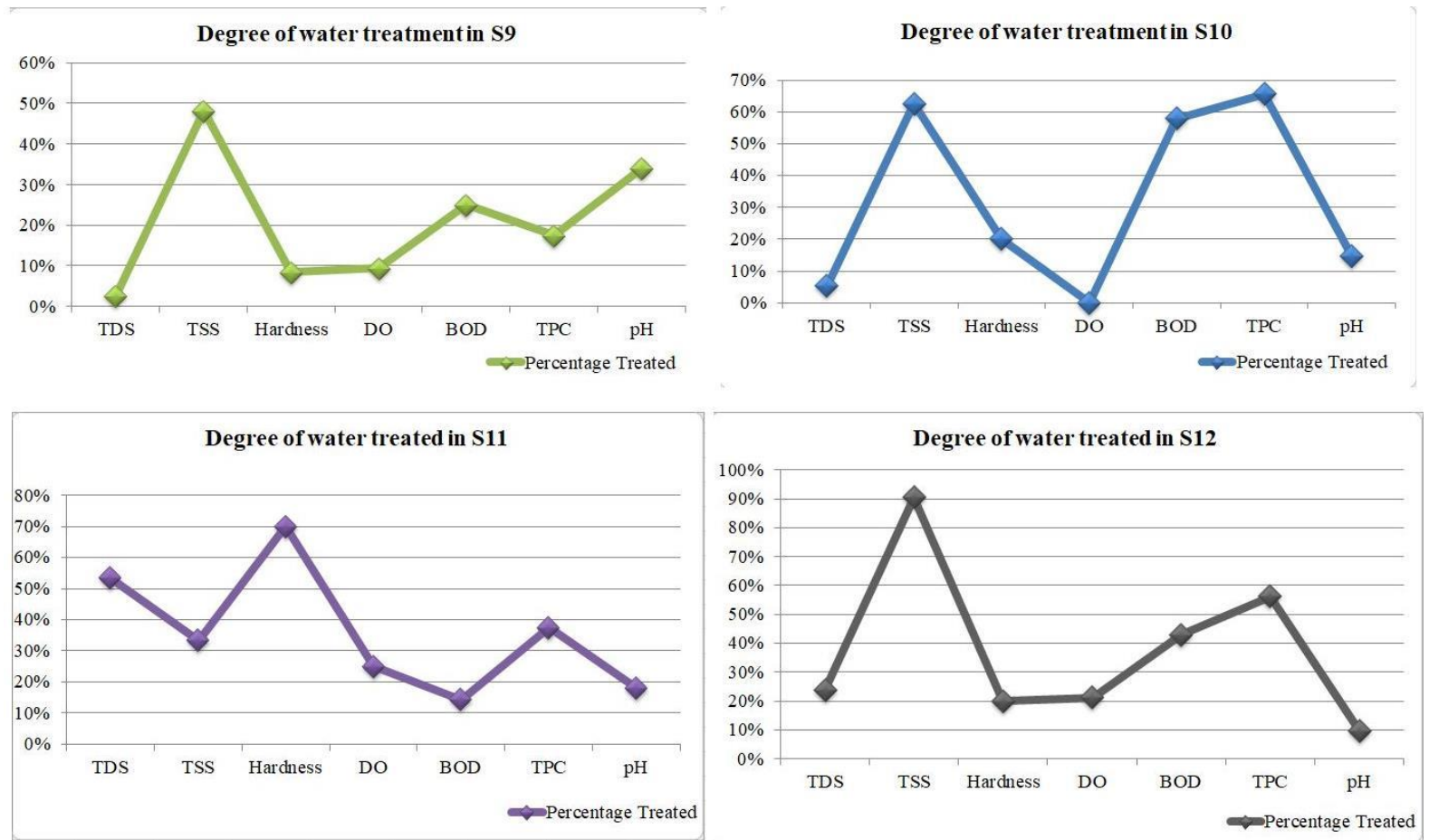

Figure 9 Efficiency of water purifiers installed in sampling stations S9, S10, S11 \& S12

Figure 10 represents the comparison of the inlet and the outlet water samples of each sampling station through a line graph. It can be observed that apart from the purified water sample of S5 (WQI value- 66.462), all other outlet samples are found to be of good quality. Treated water of S8 and S12 is of Excellent quality as per the WQI method. Except for S5, the WQI value of all the Outlet samples are lower than their Inlet water samples.

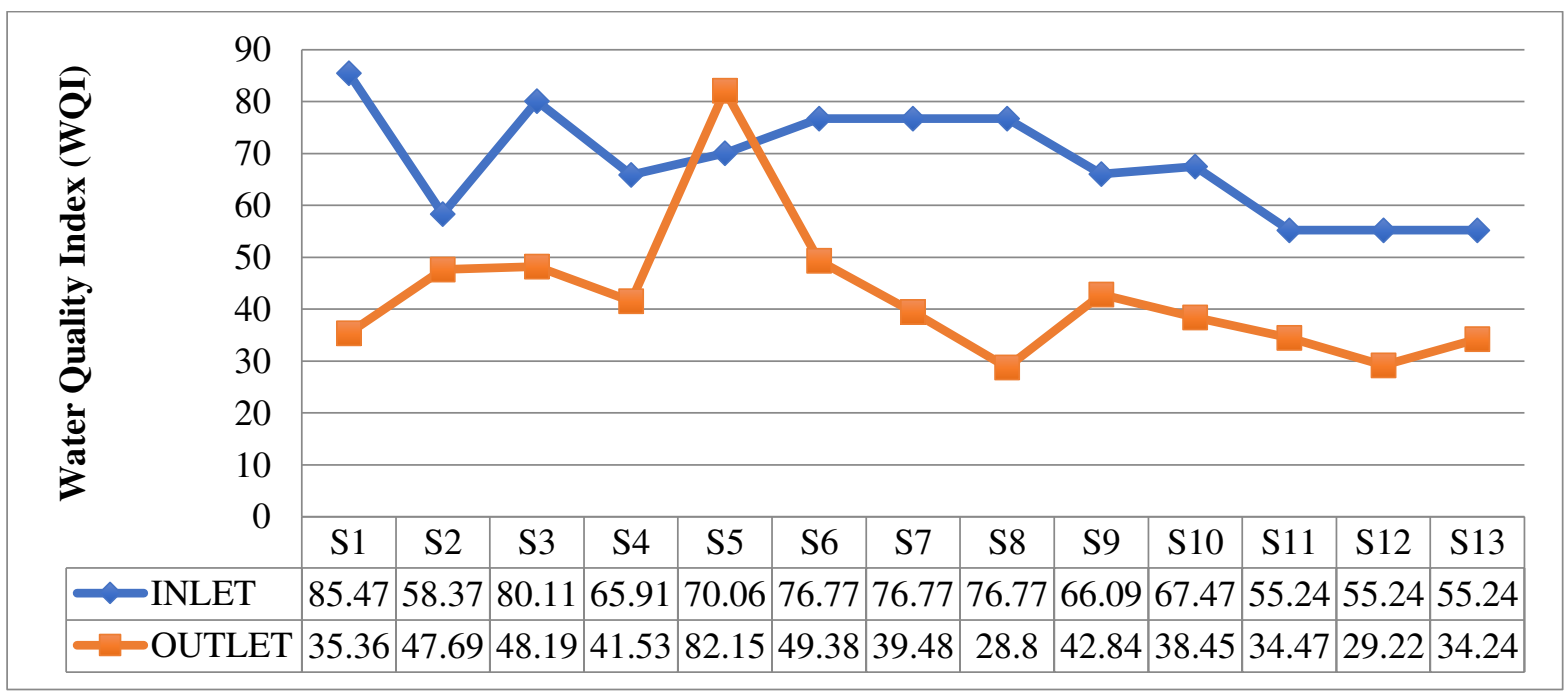

Figure 10 Line graph representing WQI values of the water samples 
The comparison between the standard WAQWI method and the MCDM-WAWQI based technique has been shown in a visual representation in figure 9. It can be observed that in the majority of the sampling stations, WQI scores obtained from the two methods are not varying significantly. Although, the tiny fluctuations in the value are due to the MCDM based weighted significance values, prioritizing the parameters based on 'Cost,' 'Potability' and 'Taste.' Moreover, modifications in the Qi formula have also improved the accuracy of the MCDM-WAWQI score as the conventional approach might not always work for water quality parameters such as $\mathrm{pH}$ and $\mathrm{DO}$.

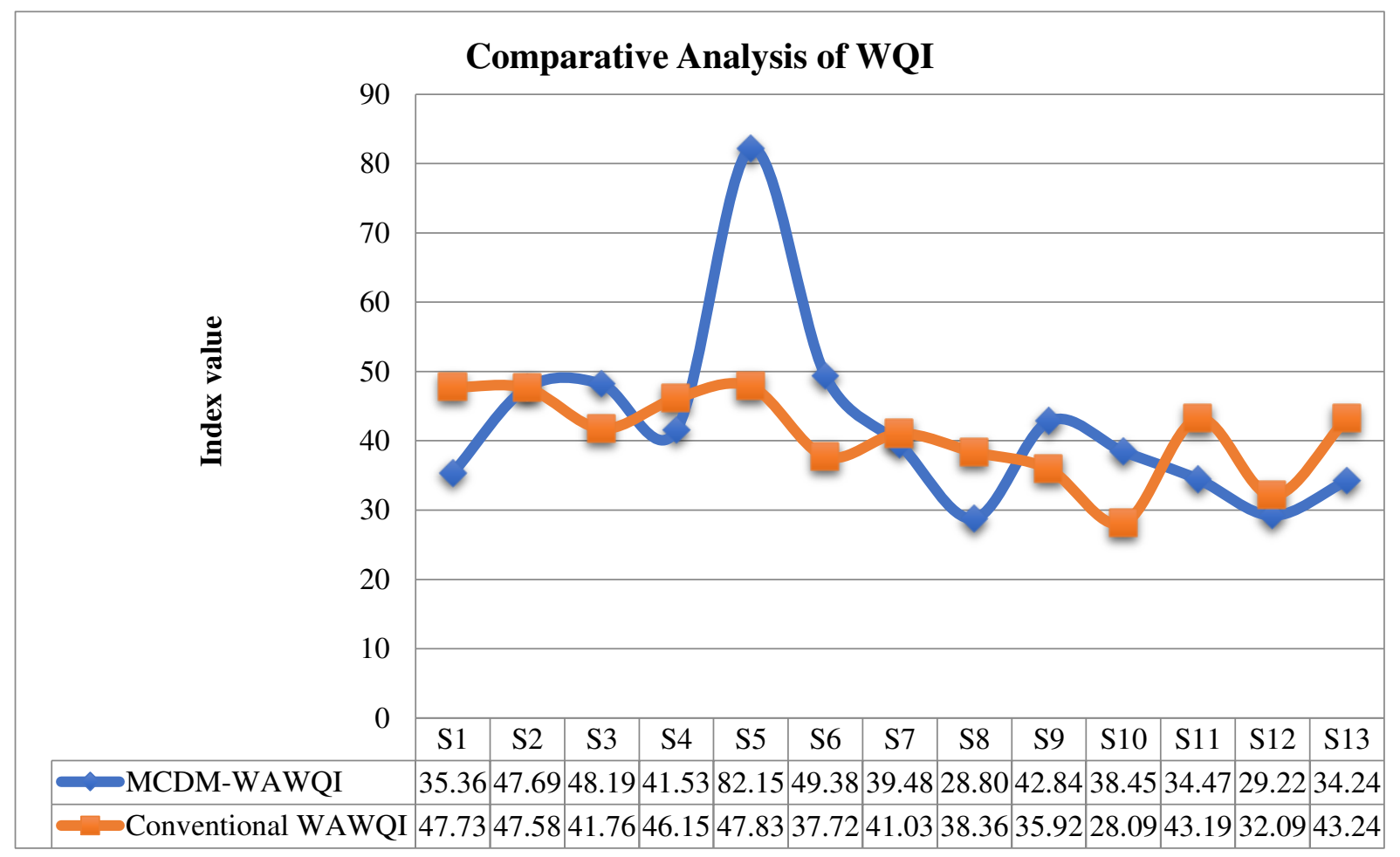

Figure 11 Comparison between proposed MCDM-WAWQI and traditional WAWQI method

A tornado diagram and spider chart have been prepared based on the OFAT Sensitivity Analysis method. All seven parameters have been varied by $+/-20 \%$, and its corresponding effect on the proposed WQI has been observed. The diagrams show that Dissolved Oxygen is the most sensitive parameter in determining WQI, followed by Total Suspended Solids, which corroborates the MCDM techniques such as AHP and ANP. 


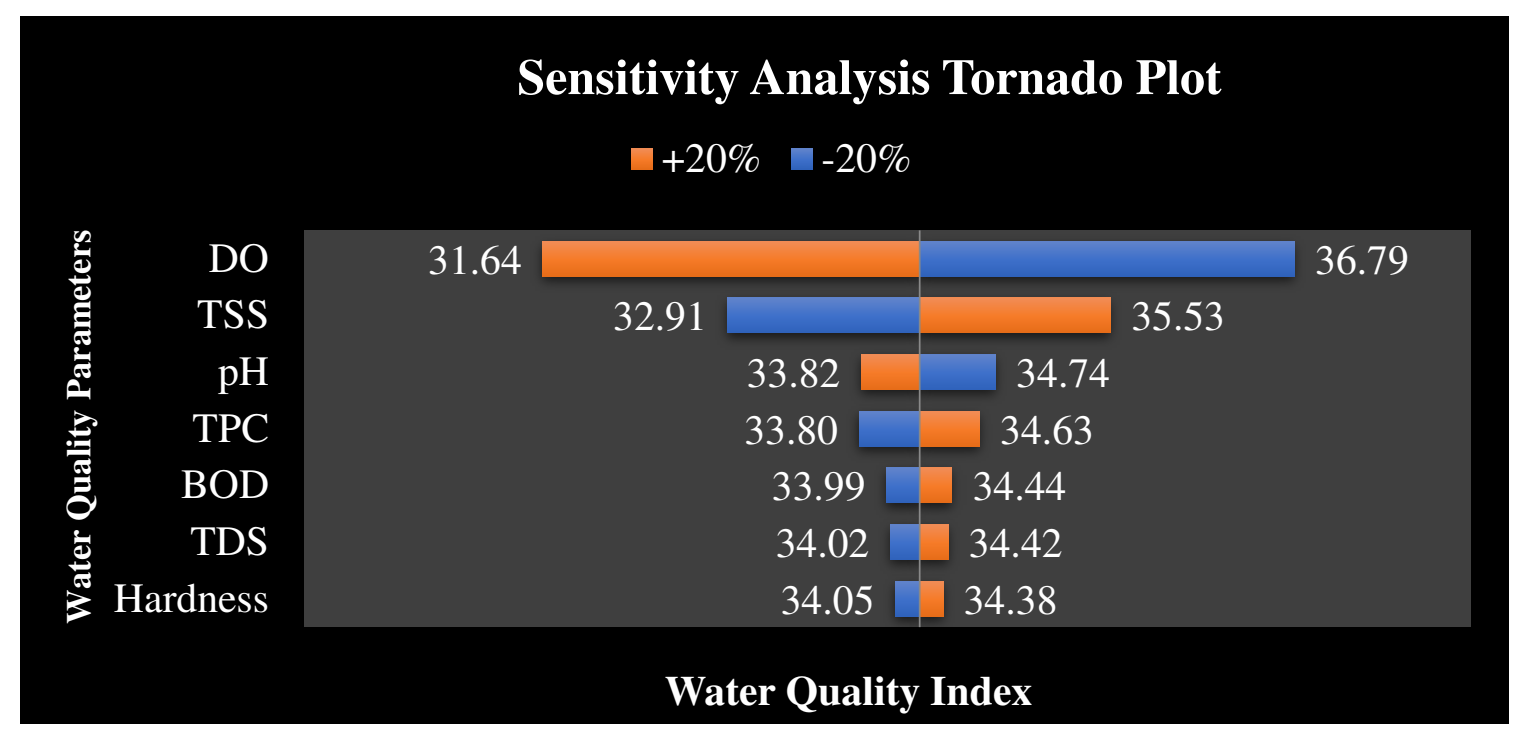

Figure 12 Sensitivity Analysis of MCDM-WAWQI approach with Tornado Diagram

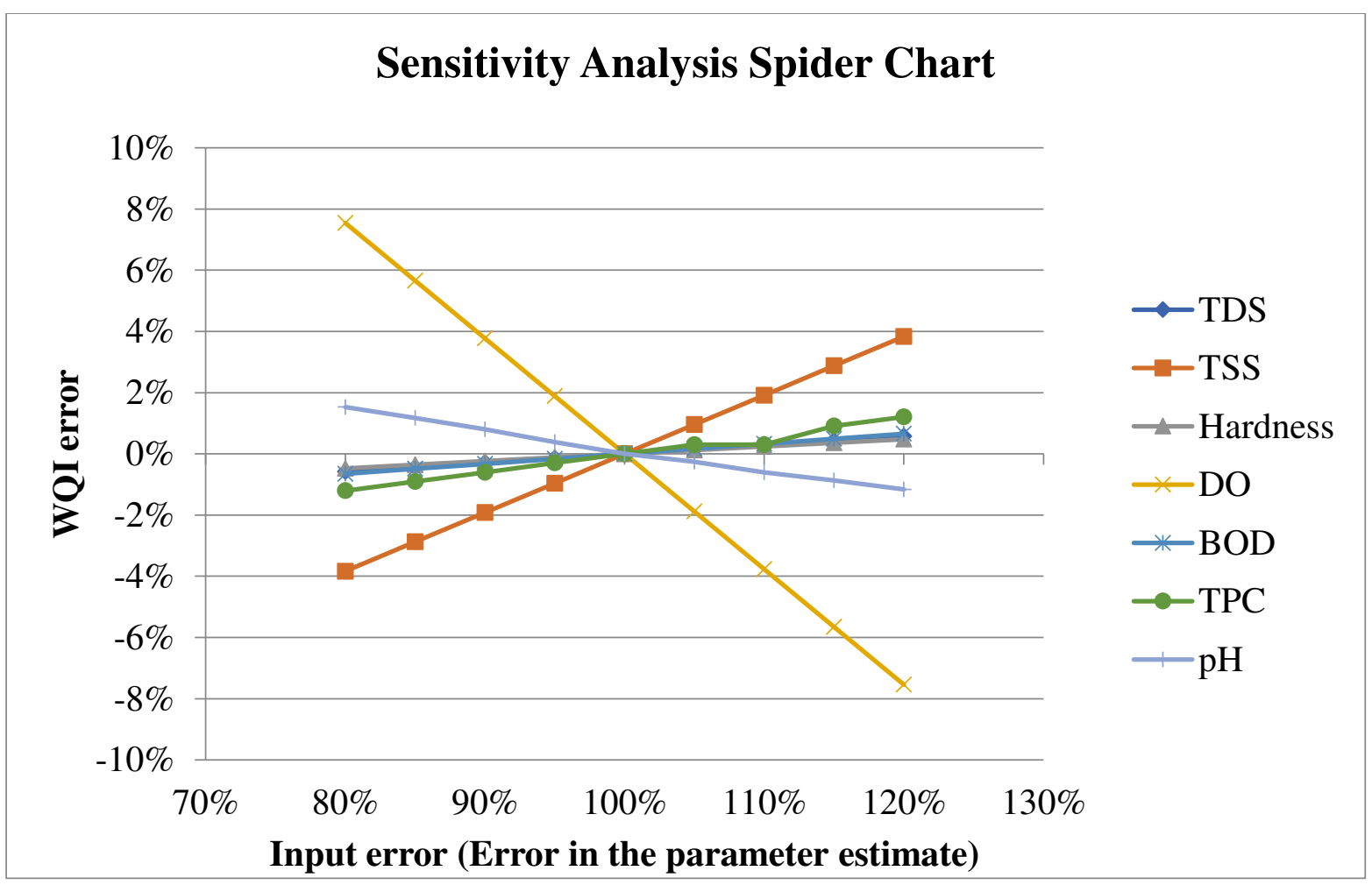

Figure 13 Sensitivity Analysis of MCDM-WAWQI approach with Spider Chart

The proficiency to attenuate the complex and varied information into a single value to convey the data in a simplified and consistent form makes the users' water quality index precious. National and internationally renowned agencies have suggested various methods to calculate WQI but have some merits and limitations. Lots of researches are going on to improve this 
iterative process of evaluating WQI. Although few Studies on MCDM based WQI have been done in the recent past, they have not considered the impact of novel criteria such as cost, Potability, and taste on the drinking water quality index. Therefore, the present investigation will approximate the WQI with AHP MCDM and validate the same comparing with ANP MCDM. The weighted aggregated measure of the seven water quality parameters will be figured out using Shannon's Entropy weighted step. This proposed approach will help improve the accuracy of estimating WQI and present the most influential parameters in maintaining water quality. Thus, the users will focus on keeping the magnitude of that parameter within the standard value.

\section{CONCLUSION}

The study aimed to suggest a new method to determine the drinking water quality index with the help of MCDM techniques. Certain modifications to the standard Weighted Arithmetic Water Quality Index (WAWQI) method were proposed to improve the accuracy and reliability of the process. Allocation of weighted values to the water quality parameters was carried out using AHP and ANP MCDM techniques. The process of assigning weights was more logical than the conventional method, which was based on permissible limits of the parameters involved in the water quality analysis. The second modification uses the absolute term in the Quality rating formula to get a more precise and justified WQI value for the concerned water. The MCDM- WAWQI method results show that most of the treated water samples accumulated from the thirteen sampling stations were of good quality. Treated water taken from S12 has the best water quality (Both Inlet and Outlet) than other blocks, whereas sampling station 5 (Outlet purified water) shows unsatisfactory results. The treated water samples of sampling stations 2 and 3 also show harmful consequences for some water quality parameters. The integration of AHP, ANP, and Shannon's Entropy techniques in the present study has shown Dissolved Oxygen as the most influential parameter in determining drinking 
water quality, followed by Total Suspended Solids. Sensitivity analysis of the proposed novel WQI technique is evaluated for validation of the new method. The results have also shown DO as the most sensitive parameter in the index calculation. While calculating relative weighted significance with the help of MCDM processes, the order of preference for the criteria is not standard or fixed. It can be inconsistent for a different section of users. Furthermore, the selection of criteria may also vary depending upon the requirement of the consumers. These factors might result in minor alterations in the value of relative weights.

\section{DECLARATION}

\section{Ethics Approval:}

The manuscript has not been submitted to more than one journal for simultaneous consideration. The submitted work is original and the work not has been published elsewhere. Results have been presented clearly, honestly, and without fabrication, falsification or inappropriate data manipulation (including image based manipulation). Institute facility has been utilized with proper permission. The details about the author group, the Corresponding Author, and the order of authors provided in the manuscript are all correct. Research articles and non-research articles have been cited appropriately and relevant literature in support of the claims has been made.

\section{Consent to participate:}

All the authors have given their consent for participating in this research work.

\section{Consent for publication:}

All the authors have given their consent for publishing this research work.

\section{Funding:}


This work did not receive any specific grant from funding agencies in the public, commercial, or not-for- profit sectors.

\section{Competing Interest:}

The authors declare that they have no known conflicting financial concern or personal relationships that could have emerged to influence the work reported in this paper.

\section{Authors' Contributions:}

DD wrote the manuscript, collected water samples and determined the relative weights for each of the selected water quality parameters using MCDM techniques. MM suggested the novel concept of the water quality index proposed in the study and carried out computations for WQI. TC conducted the data visualization techniques in the manuscript and performed the physio-chemical and biological analysis of the water samples along with DD. All authors reviewed the final manuscript.

\section{Availability of data and materials:}

Source of data has been clearly mentioned in the manuscript. 


\section{REFERENCE}

[1] Atekwana, Eliot A., Estella A. Atekwana, Rebecca S. Rowe, D. Dale Werkema Jr, and Franklyn D. Legall. "The relationship of total dissolved solids measurements to bulk electrical conductivity in an aquifer contaminated with hydrocarbon." Journal of Applied Geophysics 56, no. 4 (2004): 281-294.

[2] Chapelle, Francis H., Paul M. Bradley, Peter B. McMahon, and Bruce D. Lindsey. "What does "water quality" mean?." Groundwater 47, no. 6 (2009): 752-754.

[3] Chaurasia, Abhishek Kumar, H. K. Pandey, S. K. Tiwari, Ram Prakash, Prashant Pandey, and Arjun Ram. "Groundwater quality assessment using water quality index (WQI) in parts of Varanasi district, Uttar Pradesh, India." Journal of the Geological Society of India 92, no. 1 (2018): 76-82.

[4] Dano, Umar Lawal, Abdul-Lateef Balogun, Abdul-Nasir Matori, Khmaruzzaman Wan Yusouf, Ismaila Rimi Abubakar, Mohamed Ahmed Said Mohamed, Yusuf Adedoyin Aina, and Biswajeet Pradhan. "Flood susceptibility mapping using GIS-based analytic network process: A case study of Perlis, Malaysia." Water 11, no. 3 (2019): 615.

[5] Fondriest Environmental, Inc. "Dissolved Oxygen" (2013). Fundamentals of Environmental Measurements [online]. Available at: https://www.fondriest.com/environmental-measurements/parameters/water-quality/dissolvedoxygen

[6] Fraschina, K. "Filter Paper Method for Suspended Solids Determination." Sewage Works Journal 21, no. 2 (1949): 221-27. Accessed March 27, 2020. www.jstor.org/stable/25031051 
[7] Intelligent Computing \& Optimization, Conference proceedings ICO 2018, Springer, Cham, ISBN 978-3-030-00978-6

[8] Intelligent Computing and Optimization, Proceedings of the 2nd International Conference on Intelligent Computing and Optimization 2019 (ICO 2019), Springer International Publishing, ISBN 978-3-030-33585 -4

[9] Karakuş, Can Bülent. "Evaluation of groundwater quality in Sivas province (Turkey) using water quality index and GIS-based analytic hierarchy process." International journal of environmental health research 29, no. 5 (2019): 500-519.

[10] Khatri, Nitasha, Sanjiv Tyagi, Deepak Rawtani, Maithri Tharmavaram, and R. D. Kamboj. "Analysis and assessment of ground water quality in Satlasana Taluka, Mehsana district, Gujarat, India through application of water quality indices." Groundwater for Sustainable Development 10 (2020): 100321.

[11] Lad, Divya, Mehali Mehta, and Manisha Vashi. "Assessment of Surface Water Quality Using GIS: Case of Tapi Basin, Surat, Gujarat, India." In Applications of Geomatics in Civil Engineering, pp. 303-311. Springer, Singapore, 2020.

[12] Dutcher, L. C., and W. R. Moyle Jr. Tables for reducing bicarbonate to compute sum of determined constituents and for calculating hardness of a natural ground water. No. 60-42. 1960.

[13] Namugize, J. N., and G. P. W. Jewitt. "Sensitivity analysis for water quality monitoring frequency in the application of a water quality index for the uMngeni River and its tributaries, KwaZulu-Natal, South Africa." Water Sa 44, no. 4 (2018): 516-527. 
[14] Nandeesha, Vishal R. Khandagale, Vedamurthy B. Mahesh, Ankit Kumar Suman, and Mohan Teja Velagapudi. "Assessment of groundwater quality by integration of water quality index and GIS techniques." In AIP Conference Proceedings, vol. 2204, no. 1, p. 020026. AIP Publishing LLC, 2020.

[15] Oni, Olayiwola, and Olubunmi Fasakin. "The use of water quality index method to determine the potability of surface water and groundwater in the vicinity of a municipal solid waste dumpsite in Nigeria." American Journal of Engineering Research (AJER) 5, no. 10 (2016): 96-101.

[16] Sanders, Erin R. "Aseptic laboratory techniques: plating methods." JoVE (Journal of Visualized Experiments) 63 (2012): e3064.

[17] Sandle, T. "Microbiology laboratory techniques. Pharmaceutical Microbiology." (2016): 63-80.

[18] Tyagi, Shweta, Bhavtosh Sharma, Prashant Singh, and Rajendra Dobhal. "Water quality assessment in terms of water quality index." American Journal of water resources 1, no. 3 (2013): 34-38.

[19] TOKATLI, Cem. "Water Quality Assessment of Yazır Pond (Tekirdağ, Turkey): An Application of Water Quality Index." Biyoloji Bilimleri Araştırma Dergisi 12, no. 1 (2019): 26-29.

[20] Tuzkaya, Gülfem, Semih Önüt, Umut R. Tuzkaya, and Bahadır Gülsün. "An analytic network process approach for locating undesirable facilities: An example from Istanbul, Turkey." Journal of Environmental management 88, no. 4 (2008): 970-983.

[21] Vijaya Kumar, H., Nagraj S. Patil, and Nanjundi Prabhu. "Analysis of water quality parameters of groundwater near Ranebennur Industrial Area, Haveri district, Karnataka, 
India." In AIP Conference Proceedings, vol. 2204, no. 1, p. 020025. AIP Publishing LLC, 2020.

[22] World Health Organization. Guidelines for drinking-water quality. World Health Organization, 1993.

[23] Zhang, Yin, Ruihao Wang, Pengfei Huang, Xiaoli Wang, and Shenghui Wang. "Risk evaluation of large-scale seawater desalination projects based on an integrated fuzzy comprehensive evaluation and analytic hierarchy process method." Desalination 478 (2020): 114286. 


\section{APPENDIX 1}

Significance of Absolute sign in the proposed MCDM-WAWQI method

Conventional Weighted Arithmetic Water Quality Index method

$$
Q i=\left(\frac{(V a-V i)}{(V s-V i)}\right) \times 100
$$

$$
\text { If } p H=3 \text { and } D O=15 \mathrm{mg} / \mathrm{l}
$$

\begin{tabular}{|c|c|c|}
\hline Parameter & Qi & Value \\
\hline Total Dissolved Solids (mg/l) & {$[(32-0) /(500-0)] \times 100$} & 6.4 \\
\hline Total Suspended Solids(mg/l) & {$[(41-0) /(20-0)] \times 100$} & 205 \\
\hline Hardness (mg/l) & {$[(10-0) /(300-0)] \times 100$} & 3.33 \\
\hline Dissolved Oxygen (mg/l) & {$[(\mathbf{1 5 - 1 4 . 6}) /(\mathbf{5 - 1 4 . 6})] \times \mathbf{1 0 0}$} & $\mathbf{- 4 . 1 6 7}$ \\
\hline BOD (mg/l) & {$[(0.8-0) /(5-0)] \times 100$} & 16 \\
\hline Total Plate Count (Colonies) & {$[(248-0) /(300-0)] \times 100$} & 82.667 \\
\hline pH & {$[(\mathbf{3 - 7}) /(\mathbf{8 . 5 - 7})] \times \mathbf{1 0 0}$} & $\mathbf{- 2 6 6 . 6 7}$ \\
\hline
\end{tabular}

$$
W Q I=\sum_{i=1}^{n} \frac{W i Q i}{\sum W i}
$$

\begin{tabular}{|c|c|c|}
\hline Parameter & Wi x Qi & Value \\
\hline Total Dissolved Solids (mg/l) & $0.1 \times 6.4$ & 0.64 \\
\hline
\end{tabular}




\begin{tabular}{|c|c|c|}
\hline Total Suspended Solids(mg/l) & $0.164 \times 205$ & 33.62 \\
\hline Hardness $(\mathrm{mg} / \mathrm{l})$ & $0.152 \times 3.33$ & 0.51 \\
\hline Dissolved Oxygen (mg/l) & $0.21 \times(-4.167)$ & -0.875 \\
\hline $\mathrm{BOD}(\mathrm{mg} / \mathrm{l})$ & $0.08 \times 16$ & 1.28 \\
\hline Total Plate Count (Colonies) & $0.162 \times 82.667$ & 13.39 \\
\hline $\mathrm{pH}$ & $0.134 \times(-266.67)$ & -35.73 \\
\hline \multicolumn{2}{|c|}{ Conventional Water Quality Index (WQI) } & 12.84 \\
\hline
\end{tabular}

Proposed MCDM-WAWQI method

$$
Q i=\left|\frac{(V a-V i)}{(V s-V i)}\right| \times 100
$$

\begin{tabular}{|c|c|c|}
\hline Parameter & Qi & Value \\
\hline Total Dissolved Solids (mg/l) & $|[(32-0) /(500-0)] \times 100|$ & 6.4 \\
\hline Total Suspended Solids(mg/l) & $|[(41-0) /(20-0)] \times 100|$ & 205 \\
\hline Hardness (mg/l) & $|[(10-0) /(300-0)] \times 100|$ & 3.33 \\
\hline Dissolved Oxygen (mg/l) & $\left|\left[\frac{(15-14.6)}{(5-14.6)}\right] \times 100\right|$ & 4.167 \\
\hline BOD (mg/l) & $|[(0.8-0) /(5-0)] \times 100|$ & 16 \\
\hline Total Plate Count (Colonies) & & 82.667 \\
\hline
\end{tabular}




\begin{tabular}{|c|c|c|}
\hline $\mathrm{pH}$ & $|[(3-7)] /(8.5-7) \times 100|$ & 266.67 \\
\hline
\end{tabular}

$$
W Q I=\sum_{i=1}^{n} \frac{W i Q i}{\sum W i}
$$

\begin{tabular}{|c|c|c|}
\hline Parameter & Wi x Qi & Value \\
\hline Total Dissolved Solids (mg/l) & $0.1 \times 6.4$ & 0.64 \\
\hline Total Suspended Solids (mg/l) & $0.164 \times 205$ & 33.62 \\
\hline Hardness (mg/l) & $0.152 \times 3.33$ & 0.51 \\
\hline Dissolved Oxygen (mg/l) & $0.21 \times 4.167$ & 0.875 \\
\hline BOD (mg/l) & $0.08 \times 16$ & 1.28 \\
\hline potal Plate Count (Colonies) & $0.162 \times 82.667$ & 13.39 \\
\hline MCDM-WAWQI & & 35.73 \\
\hline & $0.134 \times 266.67$ & $\mathbf{8 6 . 0 4}$ \\
\hline
\end{tabular}

Thus, it can be observed the conventional WAWQI technique produces erroneous results (12.84) when $\mathrm{pH}$ and DO values are on extreme sides. If we abide by the WQI results, the water seems excellent, with a $\mathrm{pH}$ value being three and a DO value of 15 . Whereas in the MCDM-WAWQI method, the results are entirely satisfactory, with a value of 86.04 , which suggests that water is in poor condition. 